atmosphere ${ }^{131} \mathrm{I}$ was mainly present as gaseous species and is depleted with high efficiency by rain.

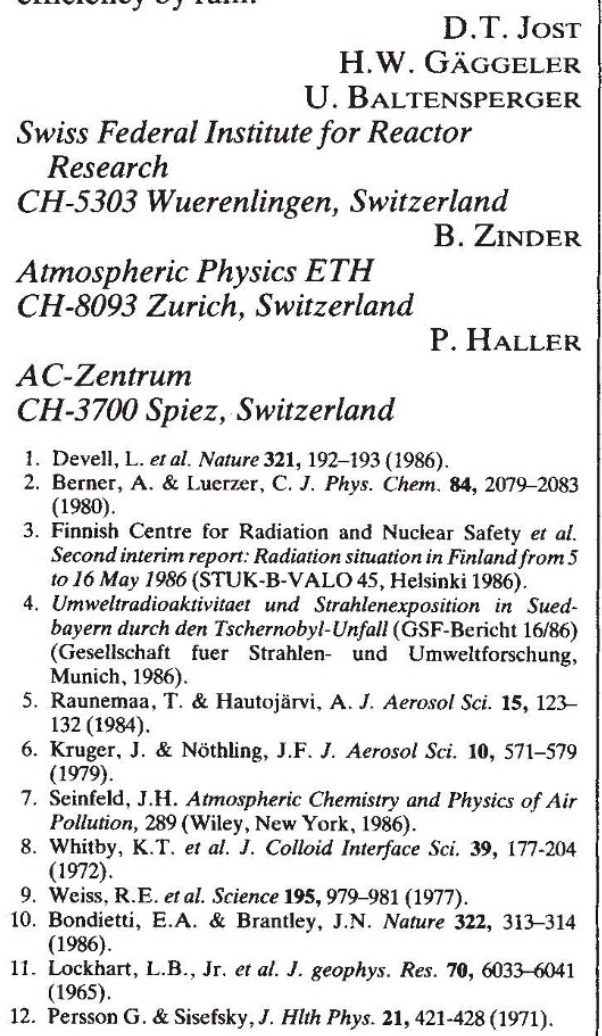

\section{Alimentary restrictions and ${ }^{131} I$ in human thyroids}

SIR-Hill et al. ${ }^{1}$ have reported measurements of ${ }^{131} I$ during the period following the Chernobyl reactor accident. We have directly determined ${ }^{131} \mathrm{I}$ activity in specimens of thyroid gland obtained at autopsy from 51 adult individuals dying of accidental causes in the area of Genoa. Sampling started on 3 May 1986, 2 days after arrival of the radioactive plume over the area and one day before an abundant rainfall.

Each thyroid specimen was placed in the central well of a shielded NaI(T1) detector connected with a 1,024-channel spectrometer; radioactivity was measured against a ${ }^{131} \mathrm{I}$ standard having the same geometry.

Differences between individuals (Fig. 1) presumably reflect variable exposure. High levels of ${ }^{131} \mathrm{I}$ were detected from the beginning of radioactive fall-out. The decay of radioactivity in the following weeks was less pronounced than expected on the basis of the effective half-life of ${ }^{131} \mathrm{I}$ in thyroid (7.55 days) (Fig. 2), inferred from its biological (120 days) and physical (8.05 days) half-life.

Although these data are consistent with some persistence of the exposure to ${ }^{131} \mathrm{I}$, the progressive decrease of radioactivity in the thyroid contrasts with the initial increase of ${ }^{131} I$ in milk samples from the same area (Fig. 2), presumably reflecting the efficacy of alimentary restrictions in-

-SCIENTIFCCORRESPONDENCE

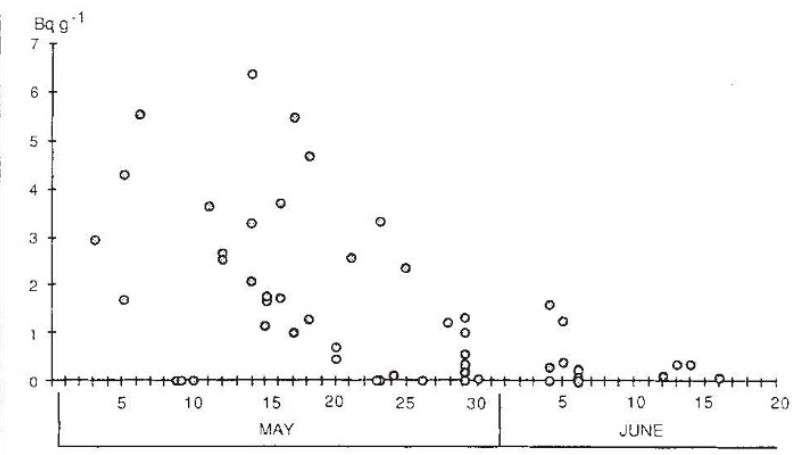

Fig. $1{ }^{131}$ I activity as measured in 51 thyroid specimens in the period following the Chernobyl accident.

Thyroid
$\left(\mathrm{Bq} \mathrm{g}^{-1}\right)$

Milk

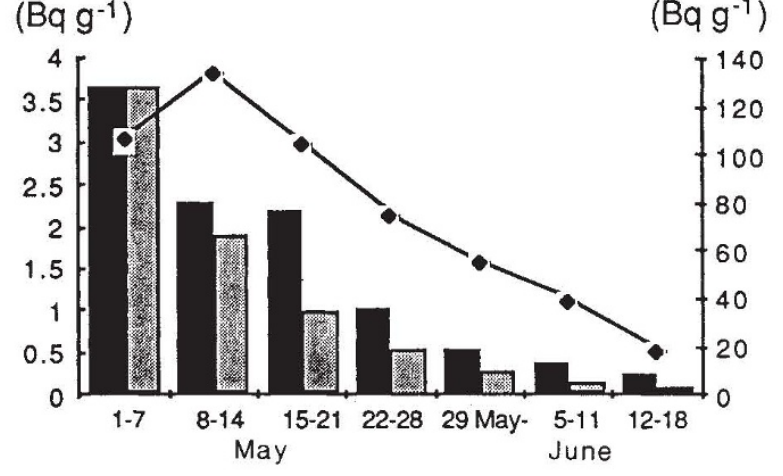

Fig. 2 Mean weekly ${ }^{131}$ I activity in milk (continuous line) and in thyroid (black columns) during the 7 weeks following arrival of the radioactive plume. Stipled columns indicate the theoretically expected decay of radioactivity, starting from the levels detected in thyroid during the first week of monitoring. troduced in Italy on 3 May. It is also significant that, on withdrawal of restrictions (16 May), the trend towards the loss of radioactivity in the thyroid was temporarily discontinued (Fig. 2).

The mean absorbed $\beta$ dose was inferred from the ${ }^{131} I$ activity measured in thyroid specimens, using an ad hoc conversion factor ${ }^{2}$. During the first 7 weeks following arrival of the radioactive plume, the mean ( \pm SD) weekly absorbed doses were 3.66 $\pm 1.68,2.31 \pm 2.12,2.20 \pm 1.61,1.02 \pm$ $1.37,0.55 \pm 0.58,0.38 \pm 0.51$, and $0.24 \pm$ $0.17 \mu \mathrm{Sv} \mathrm{g} \mathrm{g}^{-1}$ respectively. Assuming an average weight of $20 \mathrm{~g}$ per thyroid, it can be estimated that the cumulative load absorbed during that period accounted for a mean value of $207 \mu \mathrm{Sv}$ per individual. These estimates are higher than those

\section{Radioactive fallout swipe samples from Chernobyl}

SIR-Significant quantities of radioactive fallout from Chernobyl were detected in aircraft swipe samples throughout the month of May, initially on flights from Moscow and, later, from London, New York and Tokyo. Swipe samples have provided valuable information on atmospheric nuclear weapon tests ${ }^{1.2}$ in the past. The fallout from Chernobyl was measured in the swipe samples collected at Bombay from 2 May onwards. Though the radioactive plume rise at the accident site has been estimated ${ }^{3}$ to be around a kilometre, atmospheric dispersion with time could carry the activity to higher altitudes which enabled its detection.

In all, 20 isotopes; ${ }^{95} \mathrm{Zr},{ }^{95} \mathrm{Nb},{ }^{99} \mathrm{Mo}$, made for adult individuals in southern United Kingdom, where the environmental contamination, as deduced from milk ${ }^{131} \mathrm{I}$ activity, was substantially lower than in our region ${ }^{1}$.

P. ORLANDO

G. GAllelli

F. Perdelli

S. DE FLORA

Institute of Hygiene

R. Malcontenti

Institute of Forensic Medicine,

School of Medicine,

University of Genoa,

16132 Genoa, Italy

1. Hill, C.R., Adam, I., Anderson, W., Ott, R.J. \& Sowby, F.D. Nature 321, 655-656 (1986)

2. Snyder, W.S., Ford, M.R., Warner, G.G. \& Watson, S.B. MIRD pamphlet No. 11 (Society of Nuclear Medicine, New York, 1969).

${ }^{103} \mathrm{Ru},{ }^{106} \mathrm{Ru},{ }^{110 \mathrm{~m}} \mathrm{Ag},{ }^{111} \mathrm{Ag},{ }^{125} \mathrm{Sb},{ }^{127} \mathrm{Sb}$, ${ }^{132} \mathrm{Te},{ }^{131} \mathrm{I},{ }^{134} \mathrm{Cs},{ }^{136} \mathrm{Cs},{ }^{137} \mathrm{Cs},{ }^{140} \mathrm{Ba},{ }^{140} \mathrm{La}$, ${ }^{141} \mathrm{Ce},{ }^{144} \mathrm{Ce},{ }^{147} \mathrm{Nd}$ and ${ }^{239} \mathrm{~Np}$ were measured by high resolution gamma spectroscopy. Although the nature of the sampling does not permit quantification with respect to volume of air, useful information could be obtained by studying suitable radioisotope ratios.

Our results are generally similar to those reported by others ${ }^{3-6}$. Different isotopes of caesium, iodine, ${ }^{132} \mathrm{Te},{ }^{140} \mathrm{Ba}$, ${ }^{140} \mathrm{La},{ }^{103} \mathrm{Ru}$ and ${ }^{99} \mathrm{Mo}$ were the major contributors to the activities measured in the samples. Comparisons with similar swipe samples collected after the last atmospheric test in 1980 , which was a low altitude $\mathrm{H}$-bomb explosion, show that in the present case the ${ }^{137} \mathrm{Cs}$ levels are about an order of magnitude higher and ${ }^{103} \mathrm{Ru}$ 